\title{
Interventions for Non-Injection Substance Use Among US Men Who Have Sex with Men: What is Needed
}

\author{
Glenn-Milo Santos $\cdot$ Moupali Das $\cdot$ Grant Nash Colfax
}

Published online: 15 March 2011

(C) The Author(s) 2011. This article is published with open access at Springerlink.com

\section{Introduction}

Men who have sex with men (MSM) remain disproportionately infected with HIV. MSM accounted for 53\% of the 56,300 new HIV infections in the US in 2006, despite representing only $4 \%$ of the national male population $[1,2]$. This high HIV disease burden coincides with high prevalence of non-injection substance use and alcohol consumption among US MSM. A national MSM sample found a $42 \%$ previous year prevalence for any non-injection substance use [3]. The recently released United States National HIV/AIDS strategy highlights the need to address substance use among MSM as a critical component of reducing HIV incidence in the United States [4]. To advance this goal, it is imperative to: (1) redress the knowledge gaps on patterns of non-injection substance use among substance using MSM (SUMSM); (2) improve upon existing interventions; (3) develop effective, scalable interventions for the spectrum of users; and (4) determine how to best identify and address the structural and cultural factors that may contribute to non-injection substance use in the MSM population.

Non-injection substance use may increase susceptibility to HIV infection in multiple ways [5, 6]. Many epidemiological studies document the association between these substances and sexual risk behaviors [7-24]. These sexual risks are paralleled by high rates of incident and prevalent HIV cases and sexually transmitted infections among

G.-M. Santos · M. Das · G. N. Colfax ( $\square)$

San Francisco Department of Public Health, HIV Prevention Section, 25 Van Ness Avenue, Suite 500, San Francisco, CA 94102, USA

e-mail: Grant.Colfax@sfdph.org
SUMSM. Most notably, methamphetamine, cocaine, poppers, and alcohol use have each been associated with an increased risk for HIV and other STD infections [9, 12, 2430]. The contribution of polysubstance use may also be considerable $[9,28,31]$.

Patterns of Substance Use among MSM

Drug use among MSM is not an all or nothing phenomenon. There needs to be more emphasis on addressing the specific patterns of non-injection substance use among SUMSM, and what implications these patterns have for intervention approaches. Most SUMSM are not drugdependent, but rather use episodically (i.e., using substances less than weekly). National HIV Behavioral Surveillance (NHBS) data show that $69-86 \%$ of SUMSM report less than weekly substance use [32-35]. Episodic binge drinking is also common among high-risk MSM [36, 37]. Importantly, episodic patterns are associated with high-risk sexual behaviors, suggesting that while perhaps less concerning from a drug-dependence perspective, they may nonetheless contribute substantially to HIV transmission rates among SUMSM [24, 38].

Polysubstance use patterns (i.e., taking more than one substance concurrently, or periodically over a period of time) are often the norm among SUMSM. For example, exclusive of alcohol use, $93 \%$ of non-injection methamphetamine using MSM in the San Francisco NHBS sample reported polysubstance use during the prior 12 months before interview; similarly, 94\% of cocaine and $90 \%$ of poppers users reported using other substances [39]. In a sample of HIV-positive methamphetamine using MSM, $95 \%$ of respondents were polysubstance users [40]. Similar findings were reported among samples of MSM club drug users and African American MSM [41-43]. Among various 
MSM samples, 11-44\% of participants reported recent use of three or more substances [44-48].

We need to better understand how to address the wide spectrum of non-injection substance use patterns among MSM. At one extreme are the substance-dependent MSM for whom risk behavior and substance use morbidity may be especially high. Yet, there is also the larger population of MSM whose substance use is infrequent, but for whom it is associated with harmful use and HIV risk. It is unclear where on the substance use spectrum interventions should be invested to have the maximum effectiveness. There is also little understanding as to why, with overall substance use being so prevalent among MSM, only a small proportion develops dependence. Similarly, there is a paucity of understanding as to why some MSM do not use substances, and what factors confer protective effects or relative resiliency with regard to substance use [49]. Finally, how substance use patterns vary across the life trajectories of MSM and how those variations coincide with major life milestones (e.g., sexual debut, coming out, dating, aging, etc.), remains largely unexplored.

\section{Current Interventions}

\section{Interventions in Drug Treatment Settings}

SUMSM intervention trials have largely mirrored traditional addiction research, with a focus on treating those with drug dependence in substance use treatment settings. Most interventions emphasize cognitive or psychosocial approaches to reduce non-injection substance use and related risks $[5,50,51]$. Some trials focusing on treatmentseeking, methamphetamine-dependent MSM have been associated with reduced substance use and sexual risk behavior [52]. There is limited evidence that behavioral interventions with gay-specific components have a greater effect on reducing methamphetamine use, lending support for developing more culturally tailored interventions [5]. The support for contingency management's acceptability and efficacy is mixed [52, 53]. While intensive behavioral interventions appear in some cases to reduce cocaine use and sexual risk among general populations, there is little evidence of what may work best among MSM [50, 51, 54, 55]. Similarly, for alcohol, the most commonly used substance among MSM, there is a marked paucity of behavioral trials specific to the population $[56,57]$.

\section{Interventions Outside of Drug Treatment Settings}

Most SUMSM do not access drug treatment, reinforcing the need to develop interventions outside of treatment settings that may reduce HIV risk behavior [58-60].
Project MIX, one of the largest randomized controlled trials specific to SUMSM to date, tested a group intervention outside of treatment centers. The study focused on reducing sexual risk behavior, taking a risk-reduction approach rather than an abstinence-based approach. Project MIX enrolled a diverse cohort of SUMSM, including polysubstance users and SUMSM of color. Compared to an attention control arm, the intervention was not more efficacious in reducing sexual risk behaviors or substance use; substantial reductions occurred in both arms [61]. Another recent trial evaluating motivational interviewing among MSM club drug users found significant reductions in selfreported club drug use in the intervention arm compared with the control arm but only among the subset of nonseverely dependent participants. Moreover, the study found no significant differences in sexual risk reduction [62]. While these trials showed it is possible to enroll and retain SUMSM in interventions outside of drug treatment settings, and that participation is associated with reduced risk, it remains to be determined which interventions are efficacious.

\section{Pharmacologic Interventions for Dependent SUMSM}

Given their cost, potential side effects, and the potential monitoring required, it is likely that pharmaceutical treatments would be targeted to dependent SUMSM, for whom even intensive behavioral interventions may be insufficient to address the underlying chemical and psychological changes that occur as a result of drug dependency. Like any biomedical intervention, medications should not be viewed as stand-alone interventions. Pharmacotherapies may have the most potential to complement existing behavioral strategies [55, 63]. A recent NIDA-funded study conducted by our group determined that it was feasible to enroll and retain methamphetamine-dependent, actively-using MSM in a pharmacologic trial with a behavioral platform of riskreduction counseling [64]. Unfortunately, effective pharmacotherapies for most non-injection substances, including cocaine and methamphetamine, remain elusive $[5,55,65$, 66]. While a variety of medications have shown efficacy in reducing alcohol use, we are unaware of published studies demonstrating their acceptability among MSM, or their efficacy in reducing alcohol-related sexual risk behavior.

Because of the high prevalence of polysubstance use among SUMSM, medications that can help reduce dependence on various classes of drugs may be optimal. One promising option is naltrexone, an FDA approved medication to treat alcohol dependence that in one study reduced amphetamine relapse [67]. Given the potential barriers to medication adherence among non-injection substance users, interventions with adherence support and formulations that will minimize patient burden (e.g., 
slow-release intramuscular medications or non-daily dosing) could be explored [68, 69].

Future Research Directions for SUMSM Outside of Drug Treatment Settings

The Centers for Disease Control and Prevention-funded Project ECHO study is an ongoing behavioral intervention trial for non-treatment seeking MSM who are episodic substance users (clinicaltrials.gov identifier: NCT01279044) [70]. The study will determine whether brief, personalized cognitive risk-reduction counseling is effective in reducing sexual risk behavior in the setting of substance use. This study's underlying hypothesis is that a brief intervention may be sufficient to change risk among non-dependent, episodic users whose lives may be less complicated by substance abuse-related factors compared with drug-dependent MSM [70].

Specific areas that may require increased attention include settings and dimensions that facilitate non-injection substance use among MSM, such as party events, sex clubs, and websites that cultivate the "party and play" (i.e., sex with drugs) subculture. Potential interventions that may warrant further investigation include: Ghaziani and Cook's 5-by-5 circuit party matrix strategy of engaging critical circuit party stakeholders and participants by using theoretically-based harm reduction messages; Internet-based outreach strategies such as the "Cyber-Based Education and Referral/Men for Men" (CyBER/M4 M); and behavioral change theory-based risk reduction interventions delivered via mobile text messages or smartphone applications to MSM [71-74]. Other programs for SUMSM, such as support groups, economic incentive programs, and mobile harm reduction services, could be implemented and tested in community settings to engage hard to reach populations [75-77]. The effectiveness of these interventions in reducing HIV risk, substance use, and substance use-related harms needs to be proven.

\section{Addressing Other Health Needs of SUMSM}

Routine testing for HIV and other sexually transmitted infections should also be expanded among SUMSM. Given the high rates of sexual risk associated with this population, screening every 3-6 months is prudent. Other important general healthcare approaches include outreach efforts to expand HIV testing and treatment among SUMSM not engaged in care, expanding beyond partner notification to encourage for routine testing for sex partners and social network associates of SUMSM. As is the case with substance users in general, ongoing non-injection substance use should not preclude consideration of antiretroviral therapy (ART) for HIV-infected SUMSM. Aggressive efforts should be made to effectively engage HIV-positive SUMSM into care and provide support necessary for voluntary initiation of ART and attendant virologic suppression for their own individual health benefit, as well as to reduce forward transmission. The National Institute of Health's "Test and Treat" initiatives, including NIDA's support for "Seek, Test, Treat and Retain" research, may be excellent opportunities to determine how to best get SUMSM tested and into medical care [78, 79].

Additionally, SUMSM may have co-morbidities or life experiences that additively exacerbate susceptibility to HIV infection and may perpetuate substance use [49]. These may include mental illness, post-traumatic stress, sexual trauma, domestic violence and other underlying sociocultural factors [5, 49, 59, 80, 81]. How to best intervene on these multiple, intertwined and highly complex factors that converge to create "syndemics" among MSM remains an area of active research [80, 82].

\section{Structural Factors}

The structural factors that may contribute to substance use among MSM remain largely unexplored and underresearched. This is concerning because addressing these factors to improve MSM health overall may have a larger population-level impact than individual interventions [83]. Certainly, legalizing syringe exchange and making clean supplies available to injectors can be expected to benefit the SUMSM who inject [84]. However, it is unclear what other policies, laws, or social forces contribute to the high prevalence of non-injection substance use and related harms, including sexual risk, among MSM. Substance use is a largely criminalized and stigmatized practice. Evidence shows limited success from prohibitive approaches to drug control. For example, precursor regulation for methamphetamine production had mixed and mostly short-term effects on the supply and purity of the drug $[5,85]$. Decriminalization may reduce substance use-related harms [86-88]. "Wars on drugs" are expensive, have little or no apparent effect, and in some cases have led to catastrophic casualties and egregious human rights violations [5, 86, 89]. In recognition of these failures, The Vienna Declaration, released at the XVIII International AIDS Conference, calls for reorienting drug policies toward those that are evidence-based [86].

\section{Conclusion}

SUMSM are at high risk for HIV infection, yet there are critical gaps in knowledge regarding the contribution of non-injection substance use to the HIV epidemic among US MSM. The field will benefit from additional insights on 
the natural history of non-injection substance use and the predictors of different drug use trajectories. Substance treatment and HIV prevention services should be employed to address the needs of SUMSM. Efforts to develop evidence-based interventions need to be accelerated. Emphasis should be placed on finding sustainable, effective strategies that deal with non-injection substance use and risk for HIV infection. While we have focused on US MSM, emerging evidence indicates that non-injection substance use is also driving the MSM HIV epidemic in other regions; yet, the majority of intervention trials have been conducted within the US and other Western countries [5, 90-94]. Ultimately, researchers should strive to develop efficacious intervention strategies that are scalable, costeffective and sustainable for the diversity of SUMSM.

Acknowledgments The authors would like to thank Michaela Varisto for her editorial assistance. The authors were partly funded by the US National Institute for Drug Abuse (R01-DA022190).

Open Access This article is distributed under the terms of the Creative Commons Attribution Noncommercial License which permits any noncommercial use, distribution, and reproduction in any medium, provided the original author(s) and source are credited.

\section{References}

1. Hall HI, Song R, Rhodes P, Prejean J, An Q, Lee LM, et al. Estimation of HIV incidence in the United States. JAMA. 2008;300(5):520-9.

2. Purcell DW, Johnson C, Lansky A, Prejean J, Stein R, Denning P, et al. Calculating HIV and syphilis rates for risk groups: estimating the national population size of men who have sex with men. In: National STD Prevention Conference; March 10, 2010; Atlanta, GA; 2010.

3. Sanchez T, Finlayson T, Drake A, Behel S, Cribbin M, Dinenno E, et al. Human immunodeficiency virus (HIV) risk, prevention, and testing behaviors-United States, National HIV behavioral surveillance system: men who have sex with men, November 2003-April 2005. MMWR Surveill Summ. 2006;55(6):1-16.

4. ONAP. National HIV/AIDS Strategy for the United States. Washington, DC: The White House Office of National AIDS Policy; 2010.

5. Colfax G, Santos GM, Chu P, Vittinghoff E, Pluddemann A, Kumar S, et al. Amphetamine-group substances and HIV. Lancet. 2010;376(9739):458-74.

6. Drumright LN, Patterson TL, Strathdee SA. Club drugs as causal risk factors for HIV acquisition among men who have sex with men: a review. Subst Use Misuse. 2006;41(10-12):1551-601.

7. Celentano DD, Valleroy LA, Sifakis F, MacKellar DA, Hylton J, Thiede $\mathrm{H}$, et al. Associations between substance use and sexual risk among very young men who have sex with men. Sex Transm Dis. 2006;33(4):265-71.

8. Mansergh G, Shouse RL, Marks G, Guzman R, Rader M, Buchbinder S, et al. Methamphetamine and sildenafil (Viagra) use are linked to unprotected receptive and insertive anal sex, respectively, in a sample of men who have sex with men. Sex Transm Infect. 2006;82(2):131-4.
9. Plankey MW, Ostrow DG, Stall R, Cox C, Li X, Peck JA, et al. The relationship between methamphetamine and popper use and risk of HIV seroconversion in the multicenter AIDS cohort study. J Acquir Immune Defic Syndr. 2007;45(1):85-92.

10. Colfax GN, Mansergh G, Guzman R, Vittinghoff E, Marks G, Rader M, et al. Drug use and sexual risk behavior among gay and bisexual men who attend circuit parties: a venue-based comparison. J Acquir Immune Defic Syndr. 2001;28(4):373-9.

11. Koblin BA, Murrill C, Camacho M, Xu G, Liu KL, Raj-Singh S, et al. Amphetamine use and sexual risk among men who have sex with men: results from the National HIV Behavioral Surveillance Study-New York City. Subst Use Misuse. 2007;42(10):1613-28.

12. Carey JW, Mejia R, Bingham T, Ciesielski C, Gelaude D, Herbst $\mathrm{JH}$, et al. Drug use, high-risk sex behaviors, and increased risk for recent HIV infection among men who have sex with men in Chicago and Los Angeles. AIDS Behav. 2008;13:1084-96.

13. Hirshfield S, Remien RH, Humberstone M, Walavalkar I, Chiasson MA. Substance use and high-risk sex among men who have sex with men: a national online study in the USA. AIDS Care. 2004;16(8):1036-47.

14. Woody GE, Donnell D, Seage GR, Metzger D, Marmor M, Koblin BA, et al. Non-injection substance use correlates with risky sex among men having sex with men: data from HIVNET. Drug Alcohol Depend. 1999;53(3):197-205.

15. Mimiaga MJ, Reisner SL, Fontaine YM, Bland SE, Driscoll MA, Isenberg $\mathrm{D}$, et al. Walking the line: stimulant use during sex and HIV risk behavior among Black urban MSM. Drug Alcohol Depend. 2010;110(1-2):30-7.

16. Vanable PA, McKirnan DJ, Buchbinder SP, Bartholow BN, Douglas JM Jr, Judson FN, et al. Alcohol use and high-risk sexual behavior among men who have sex with men: the effects of consumption level and partner type. Health Psychol. 2004;23(5): 525-32.

17. Irwin TW, Morgenstern J, Parsons JT, Wainberg M, Labouvie E. Alcohol and sexual HIV risk behavior among problem drinking men who have sex with men: An event level analysis of timeline followback data. AIDS Behav. 2006;10(3):299-307.

18. Purcell DW, Parsons JT, Halkitis PN, Mizuno Y, Woods WJ. Substance use and sexual transmission risk behavior of HIVpositive men who have sex with men. J Subst Abuse. 2001; 13(1-2):185-200.

19. Ober A, Shoptaw S, Wang PC, Gorbach P, Weiss RE. Factors associated with event-level stimulant use during sex in a sample of older, low-income men who have sex with men in Los Angeles. Drug Alcohol Depend. 2009;102(1-3):123-9.

20. Taylor MM, Aynalem G, Smith LV, Montoya J, Kerndt P. Methamphetamine use and sexual risk behaviours among men who have sex with men diagnosed with early syphilis in Los Angeles County. Int J STD AIDS. 2007;18(2):93-7.

21. Newman PA, Rhodes F, Weiss RE. Correlates of sex trading among drug-using men who have sex with men. Am J Public Health. 2004;94(11):1998-2003.

22. Choi KH, Operario D, Gregorich SE, McFarland W, MacKellar D, Valleroy L. Substance use, substance choice, and unprotected anal intercourse among young Asian American and Pacific Islander men who have sex with men. AIDS Educ Prev. 2005;17(5):418-29.

23. Semple SJ, Zians J, Strathdee SA, Patterson TL. Sexual marathons and methamphetamine use among HIV-positive men who have sex with men. Arch Sex Behav. 2009;38(4):583-90.

24. Woolf SE, Maisto SA. Alcohol use and risk of HIV infection among men who have sex with men. AIDS Behav. 2009;13(4): 757-82.

25. Page-Shafer K, Veugelers PJ, Moss AR, Strathdee S, Kaldor JM, van Griensven GJ. Sexual risk behavior and risk factors for HIV1 seroconversion in homosexual men participating in the 
Tricontinental Seroconverter Study, 1982-1994. Am J Epidemiol. 1997;146(7):531-42.

26. Hirshfield S, Remien RH, Walavalkar I, Chiasson MA. Crystal methamphetamine use predicts incident STD infection among men who have sex with men recruited online: a nested casecontrol study. J Med Internet Res. 2004;6(4):e41.

27. Buchbinder SP, Vittinghoff E, Heagerty PJ, Celum CL, Seage GR 3rd, Judson FN, et al. Sexual risk, nitrite inhalant use, and lack of circumcision associated with HIV seroconversion in men who have sex with men in the United States. J Acquir Immune Defic Syndr. 2005;39(1):82-9.

28. Ostrow DG, Plankey MW, Cox C, Li X, Shoptaw S, Jacobson LP, et al. Specific sex drug combinations contribute to the majority of recent HIV seroconversions among MSM in the MACS. J Acquir Immune Defic Syndr. 2009;51(3):349-55.

29. Koblin BA, Husnik MJ, Colfax G, Huang Y, Madison M, Mayer $\mathrm{K}$, et al. Risk factors for HIV infection among men who have sex with men. AIDS. 2006;20(5):731-9.

30. Van Tieu H, Koblin BA. HIV, alcohol, and noninjection drug use. Curr Opin HIV AIDS. 2009;4(4):314-8.

31. Greenwood GL, White EW, Page-Shafer K, Bein E, Osmond DH, Paul J, et al. Correlates of heavy substance use among young gay and bisexual men: The San Francisco Young Men's Health Study. Drug Alcohol Depend. 2001;61(2):105-12.

32. Bingham T. (emailed Personal Communication). Recipient: Colfax GN. Los Angeles County Department of Public Health; 2007.

33. Prachand N. (emailed Personal Communication). Recipient: Colfax GN. Chicago Department of Public Health; 2007.

34. Raymond H. (emailed Personal Communication). Recipient: Colfax GN. San Francisco Department of Public Health; 2007.

35. Sifakis F. (emailed Personal Communication). Recipient: Colfax GN. Johns Hopkins Bloomberg School of Public Health; 2007.

36. Colfax G, Vittinghoff E, Husnik MJ, McKirnan D, Buchbinder S, Koblin B, et al. Substance use and sexual risk: a participant- and episode-level analysis among a cohort of men who have sex with men. Am J Epidemiol. 2004;159(10):1002-12.

37. NYCDOHMH. Alcohol use and risky sex in New York City. New York City: New York City Department of Health and Mental Hygiene. 2008;7(6):1-4.

38. Colfax G, Coates TJ, Husnik MJ, Huang Y, Buchbinder S, Koblin $\mathrm{B}$, et al. Longitudinal patterns of methamphetamine, popper (amyl nitrite) and cocaine use and high-risk sexual behavior among a cohort of San Francisco men who have sex with men. J Urban Health. 2005;82(1 Suppl 1):i62-70.

39. Chen YH. Substance use in NHBS Data (emailed Personal Communication). Recipient: Santos GM. San Francisco Department of Public Health; 2009.

40. Patterson TL, Semple SJ, Zians JK, Strathdee SA. Methamphetamine-using HIV-positive men who have sex with men: correlates of polydrug use. J Urban Health. 2005;82(1 Suppl 1):i120-6.

41. Halkitis PN, Palamar JJ. Multivariate modeling of club drug use initiation among gay and bisexual men. Subst Use Misuse. 2008;43(7):871-9.

42. Lee SJ, Galanter M, Dermatis H, McDowell D. Circuit parties and patterns of drug use in a subset of gay men. J Addict Dis. 2003;22(4):47-60.

43. Mimiaga MJ, Reisner SL, Vanderwarker R, Gaucher MJ, O'Connor CA, Medeiros MS, et al. Polysubstance use and HIV/ STD risk behavior among Massachusetts men who have sex with men accessing Department of Public Health mobile van services: implications for intervention development. AIDS Patient Care STDS. 2008;22(9):745-51.

44. Stall R, Paul JP, Greenwood G, Pollack LM, Bein E, Crosby GM, et al. Alcohol use, drug use and alcohol-related problems among men who have sex with men: the Urban Men's Health Study. Addiction. 2001;96(11):1589-601.
45. Halkitis PN, Palamar JJ, Mukherjee PP. Poly-club-drug use among gay and bisexual men: a longitudinal analysis. Drug Alcohol Depend. 2007;89(2-3):153-60.

46. Thiede H, Valleroy LA, MacKellar DA, Celentano DD, Ford WL, Hagan $\mathrm{H}$, et al. Regional patterns and correlates of substance use among young men who have sex with men in 7 US urban areas. Am J Public Health. 2003;93(11):1915-21.

47. Operario D, Choi KH, Chu PL, McFarland W, Secura GM, Behel $\mathrm{S}$, et al. Prevalence and correlates of substance use among young Asian Pacific Islander men who have sex with men. Prev Sci. 2006;7(1):19-29.

48. Halkitis PN, Moeller RW, Siconolfi DE, Jerome RC, Rogers M, Schillinger J. Methamphetamine and poly-substance use among gym-attending men who have sex with men in New York City. Ann Behav Med. 2008;35(1):41-8.

49. Wolitski RJ, Stall R, Valdiserri R. Unequal Opportunity: health disparities affecting gay and bisexual men in the United States. New York: Oxford Press; 2008.

50. Knapp WP, Soares BG, Farrel M, Lima MS. Psychosocial interventions for cocaine and psychostimulant amphetamines related disorders. Cochrane Database Syst Rev 2007;(3): CD003023.

51. Shearer J. Psychosocial approaches to psychostimulant dependence: a systematic review. J Subst Abuse Treat. 2007;32(1): $41-52$.

52. Shoptaw S, Reback CJ, Peck JA, Yang X, Rotheram-Fuller E, Larkins $S$, et al. Behavioral treatment approaches for methamphetamine dependence and HIV-related sexual risk behaviors among urban gay and bisexual men. Drug Alcohol Depend. 2005;78(2):125-34.

53. Menza TW, Jameson DR, Hughes JP, Colfax GN, Shoptaw S, Golden MR. Contingency management to reduce methamphetamine use and sexual risk among men who have sex with men: a randomized controlled trial. BMC Public Health. 2010;10(1):774.

54. Sterk CE, Theall KP, Elifson KW. Effectiveness of a risk reduction intervention among African American women who use crack cocaine. AIDS Educ Prev. 2003;15(1):15-32.

55. Kampman KM. What's new in the treatment of cocaine addiction? Curr Psychiatry Rep. 2010;12(5):441-7.

56. Macgowan MJ, Engle B. Evidence for optimism: behavior therapies and motivational interviewing in adolescent substance abuse treatment. Child Adolesc Psychiatr Clin N Am. 2010;19(3):527-45.

57. Moyer A, Finney JW, Swearingen CE, Vergun P. Brief interventions for alcohol problems: a meta-analytic review of controlled investigations in treatment-seeking and non-treatmentseeking populations. Addiction. 2002;97(3):279-92.

58. Shallow S. Persons attending substance abuse treatment programs. San Francisco: San Francisco Department of Public Health Community Behavioral Health Agency; 2004.

59. Salomon EA, Mimiaga MJ, Husnik MJ, Welles SL, Manseau MW, Montenegro AB, et al. Depressive symptoms, utilization of mental health care, substance use and sexual risk among young men who have sex with men in EXPLORE: implications for agespecific interventions. AIDS Behav. 2009;13(4):811-21.

60. Mackesy-Amiti ME, Fendrich M, Johnson TP. Substance-related problems and treatment among men who have sex with men in comparison to other men in Chicago. J Subst Abuse Treat. 2009;36(2):227-33.

61. Mansergh G, Koblin BA, McKirnan DJ, Hudson SM, Flores SA, Wiegand RE, et al. An intervention to reduce HIV risk behavior of substance-using men who have sex with men: a two-group randomized trial with a nonrandomized third group. PLoS Med. 2010;7(8):e1000329.

62. Morgenstern J, Bux DA Jr, Parsons J, Hagman BT, Wainberg M, Irwin $\mathrm{T}$. Randomized trial to reduce club drug use and HIV risk 
behaviors among men who have sex with men. J Consult Clin Psychol. 2009;77(4):645-56.

63. Degenhardt L, Mathers B, Vickerman P, Rhodes T, Latkin C, Hickman M. Prevention of HIV infection for people who inject drugs: why individual, structural, and combination approaches are needed. Lancet. 2010;376(9737):285-301.

64. Das M, Santos D, Matheson T, Santos GM, Chu P, Vittinghoff E, et al. Feasibility and acceptability of a phase II randomized pharmacologic intervention for methamphetamine dependence in high-risk men who have sex with men. AIDS. 2010;24(7):9911000 .

65. Sofuoglu M. Cognitive enhancement as a pharmacotherapy target for stimulant addiction. Addiction. 2010;105(1):38-48.

66. Karila L, Weinstein A, Aubin HJ, Benyamina A, Reynaud M, Batki SL. Pharmacological approaches to methamphetamine dependence: a focused review. Br J Clin Pharmacol. 2010;69(6): 578-92.

67. Jayaram-Lindstrom N, Hammarberg A, Beck O, Franck J. Naltrexone for the treatment of amphetamine dependence: a randomized, placebo-controlled trial. Am J Psychiatry. 2008; 165(11):1442-8.

68. Colfax G, Guzman R. Club drugs and HIV infection: a review. Clin Infect Dis. 2006;42(10):1463-9.

69. Reback CJ, Larkins S, Shoptaw S. Methamphetamine abuse as a barrier to HIV medication adherence among gay and bisexual men. AIDS Care. 2003;15(6):775-85.

70. Das M, Dadasovich R, Matheson T, Santos GM, Gelaude D, Herbst $\mathrm{J}$, et al. Adapting an effective HIV prevention intervention, personalized cognitive counseling, for episodic substanceusing men who have sex with men (SUMSM). In: XVIII International AIDS Conference; 14 July 2010; Vienna, Austria. Abstract \#WEPE03242010; 2010.

71. Ghaziani A, Cook TD. Reducing HIV infections at circuit parties: from description to explanation and principles of intervention design. J Int Assoc Physicians AIDS Care (Chic Ill). 2005;4(2): 32-46.

72. Rhodes SD, Hergenrather KC, Duncan J, Vissman AT, Miller C, Wilkin AM, et al. A pilot intervention utilizing Internet chat rooms to prevent HIV risk behaviors among men who have sex with men. Public Health Rep. 2010;125(Suppl 1):29-37.

73. Reback CJ, Ling D, Shoptaw S, Rohde J. Developing a text messaging risk reduction intervention for methamphetamineusing MSM: research note. Open AIDS J. 2010;4:116-22.

74. Baume M. HIV prevention efforts go mobile. San Francisco: Bay Area Reporter; Benro Enterprises, Inc.; 2010 [updated December 2, 2010; cited January 12, 2011]; Available from: http://www. ebar.com/news/article.php?sec=news\&article $=5281$.

75. Lyons T, Chandra G, Goldstein J. Stimulant use and HIV risk behavior: the influence of peer support group participation. AIDS Educ Prev. 2006;18(5):461-73.

76. Shoptaw S, Klausner JD, Reback CJ, Tierney S, Stansell J, Hare $\mathrm{CB}$, et al. A public health response to the methamphetamine epidemic: the implementation of contingency management to treat methamphetamine dependence. BMC Public Health. 2006;6:214.

77. Rose VJ, Raymond HF, Kellogg TA, McFarland W. Assessing the feasibility of harm reduction services for MSM: the late night breakfast buffet study. Harm Reduct J. 2006;3:29.
78. Dieffenbach $\mathrm{CW}$, Fauci AS. Universal voluntary testing and treatment for prevention of HIV transmission. JAMA. 2009;301(22):2380-2.

79. Volkow ND, Montaner J. Enhanced HIV testing, treatment, and support for HIV-infected substance users. JAMA. 2010;303(14): $1423-4$.

80. Stall R, Mills TC, Williamson J, Hart T, Greenwood G, Paul J, et al. Association of co-occurring psychosocial health problems and increased vulnerability to HIV/AIDS among urban men who have sex with men. Am J Public Health. 2003;93(6):939-42.

81. Glick SN, Golden MR. Persistence of racial differences in attitudes toward homosexuality in the United States. J Acquir Immune Defic Syndr. 2010;55(4):516-23.

82. Stall R, Frieden M, Catania J. An update on syndemic theory among urban gay men. Washington: American Public Health Association. Abstract \#1558542007; 2007.

83. Frieden TR. A framework for public health action: the health impact pyramid. Am J Public Health. 2010;100(4):590-5.

84. Strathdee SA, Hallett TB, Bobrova N, Rhodes T, Booth R, Abdool R, et al. HIV and risk environment for injecting drug users: the past, present, and future. Lancet. 2010;376(9737):268-84.

85. McKetin R. Methamphetamine precursor regulation: are we controlling or diverting the drug problem? Addiction. 2008; 103(4):521-3.

86. Wood E, Werb D, Kazatchkine M, Kerr T, Hankins C, Gorna R, et al. Vienna Declaration: a call for evidence-based drug policies. Lancet. 2010;376(9738):310-2.

87. Moreno JG, Licea JA, Ajenjo CR. Tackling HIV and drug addiction in Mexico. Lancet. 2010;376(9740):493-5.

88. Beyrer C, Malinowska-Sempruch K, Kamarulzaman A, Kazatchkine M, Sidibe M, Strathdee SA. Time to act: a call for comprehensive responses to HIV in people who use drugs. Lancet. 2010;376(9740):551-63.

89. Jurgens R, Csete J, Amon JJ, Baral S, Beyrer C. People who use drugs, HIV, and human rights. Lancet. 2010;376(9739):475-85.

90. Morineau G, Nugrahini N, Riono P, Nurhayati, Girault P, Mustikawati DE, et al. Sexual risk taking, STI and HIV prevalence among men who have sex with men in six Indonesian cities. AIDS and Behavior. 2009. doi:10.1007/s10461-009-9590-6.

91. Bautista CT, Sanchez JL, Montano SM, Laguna-Torres VA, Lama JR, Kusunoki L, et al. Seroprevalence of and risk factors for HIV-1 infection among South American men who have sex with men. Sex Transm Infect. 2004;80(6):498-504.

92. van Griensven F, Thienkrua W, Sukwicha W, Wimonsate W, Chaikummao S, Varangrat A, et al. Sex frequency and sex planning among men who have sex with men in Bangkok, Thailand: implications for pre- and post-exposure prophylaxis against HIV infection. J Int AIDS Soc. 2010;13:13.

93. Lane T, Raymond HF, Dladla S, Rasethe J, Struthers H, McFarland W, et al. High HIV prevalence among men who have sex with men in Soweto, South Africa: results from the Soweto men's study. AIDS and Behavior. 2009. doi:10.1007/s10461009-9598-y.

94. Parry C, Petersen P, Dewing S, Carney T, Needle R, Kroeger K, et al. Rapid assessment of drug-related HIV risk among men who have sex with men in three South African cities. Drug Alcohol Depend. 2008;95(1-2):45-53. 